\title{
REVISTA
}

APOTHEKE

\section{ATO CRIADOR, BLOCOS DE EXPERIMENTAÇÕES}

\author{
Lucimar Bello Frange \\ lucimarbello@terra.com.br
}

\section{Resumo}

A pintura, na contemporaneidade, pode ser abordada por diferentes modos e com inúmeras conexões. Nesse texto, faço recortes e esboços, elos entre pintura, arquivo, condensação, multiplicidade, fugas, escapatórias. É um exercício que enfatiza, entre outros artistas, a obra Atlas de Gerhard Richter e suas muitas camadas com o mundo "real" e o mundo "com-figurado" em imagens agregadas em pranchas de papel. Richter faz a pintura re-existir.

\section{Introdução}

.. um pensamento é como um vento que nos impele,
uma série de rajadas e de abalos.
Pensa-se estar no porto,
e de novo é lançado em alto mar.
Leibniz

Do papel branco à cor. Do papel branco à matéria. Do papel branco, a um bloco de experimentações. Assim se faz uma imagem.

De uma sala vazia a uma intervenção. De uma praça chamada de nua, à experimentações colaborativas. Assim se faz uma interinvenção.

De uma sala de aula, sem mesas, sem cadeiras, a corpos criativos e vibráteis. Assim se criam imagens, palavras, ações corpóreas e compar-trilhadas.

De muitas imagens colecionadas durante 50 anos, às imagens agregadas de maneiras inusuais. Assim, Gerhard Richter opera re-existências além de pictóricas, reconfigura a pintura na contemporaneidade. 


\section{《)}

Essas possíveis constituições de territórios, quer no papel, quer no espaço coletivo, rua, cidade, escola, espaços culturais, são ações em com-junto(s). São superfícies, tempos fabricados com sabor e saberes, praticados com muita maquinação (atos incessantes de engenhocas para tecer e sustentar uma vida). São conexões de corpos vazantes pela mão, pelo gesto, pelo corpo/inteiro, expandido e ampliado - corpos sócio-culturais - em ação. São instâncias que se fazem acontecer a partir de uma necessidade pessoal/coletiva. Uma necessidade de arte como expressão e expansão da vida, no espaço, no tempo, em qualquer lugar. Lugar é um espaço praticado, experienciado. Um pintor não diz: vou pintar um quadro. Ele tem que ter uma necessidade. Inventa blocos de movimento-duração, blocos de conceitos, blocos de linha e cor (Gilles Deleuze, 1995). Acrescento os blocos matéricos (transformações dos materiais) e blocos existenciais, ancorados em uma biodiversidade. O que chamamos de "óleo sobre tela", é além do óleo e além da tela. A tela, o óleo, as camadas, os aglutinantes, o tecido, os gestos, os pensamentos, o assunto, a época, o contexto, o percurso do artista - todos são constituintes de um espaço/tempo "ali congelado" sob uma figura, uma imagem, uma pintura, uma ambiência (instalação, intervenção, performance, etc). Imagens congeladas apenas numa primeira visada. No momento em que as penetramos, as escutamos e as colocamos no corpo, elas entram, fincam, ficam, escapam entre vidas arrumadas em prateleiras, estantes, móveis em pilhas, pequenos objetos e mundos dos afetos de fazer qualquer coisa.

\section{A pintura de re-existências em Gerhard Richter}

Arrumar a vida, por prateleiras na vontade e na ação. Quero fazer isso agora,

ISSN: 2447-1267 Santa Catarina, v.2, n.2, ano 2, fevereiro de 2016. 


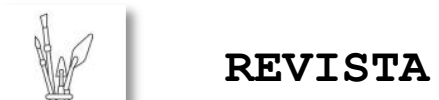 \\ A. APOTHEKE
}

\author{
como sempre quis, \\ com o mesmo resultado. \\ Mas que bom ter o propósito claro, \\ firme só na clareza, \\ de fazer qualquer coisa! \\ Fernando Pessoa.
}

Na trajetória criadora de um artista, podemos perceber as complexidades existenciais e matéricas imbricadas numa "aparente pintura". Um quadro vem de muito longe, de muitos espaços, muitos lugares, muitos tempos, muitas necessidades complexas que combinam, exigem e acampam em blocos de experimentações fugidias e escapatórias, muitas prateleiras, propósitos firmes e clareza de fazer qualquer coisa (reafirmo). Uma instalação em salas e salas contíguas, repletas de imagens agrupadas, no Atlas de Gerhard Richter, cria um mundo a ser penetrado, escarajunchado, escaravatado, re-vigorado. Picasso afirmou: eu não busco, eu encontro... Dizer que um quadro acabou? Um quadro vem de muito longe. Seria preciso toda uma vida para explicá-lo. Atlas de Richter vem de muitos longes-guardados, para quaisquer coisas a devir. Anos de esperas quase arqueológicas, para se tornarem pintura re-inventada; milhares de instantes decantados num lugar e numa "denominada exposição" - um expor/existir imantado de conexões infinitas, mares altos sem fim, gravetos e gravanhas, experimentados por Richter, experienciados por nós, vedoresledores-cúmplices de Atlas, a re-inventar e compor mundos in.com.possíveis. Agamben insiste que a única forma de compreender as raízes da profunda crise de legitimidade pela qual passamos hoje é através de uma rigorosa arqueologia das raízes da modernidade, uma arqueologia que passa a um só tempo pela política, pela teologia, pela história e pela escatologia. 


\section{REVISTA}

APOTHEKE

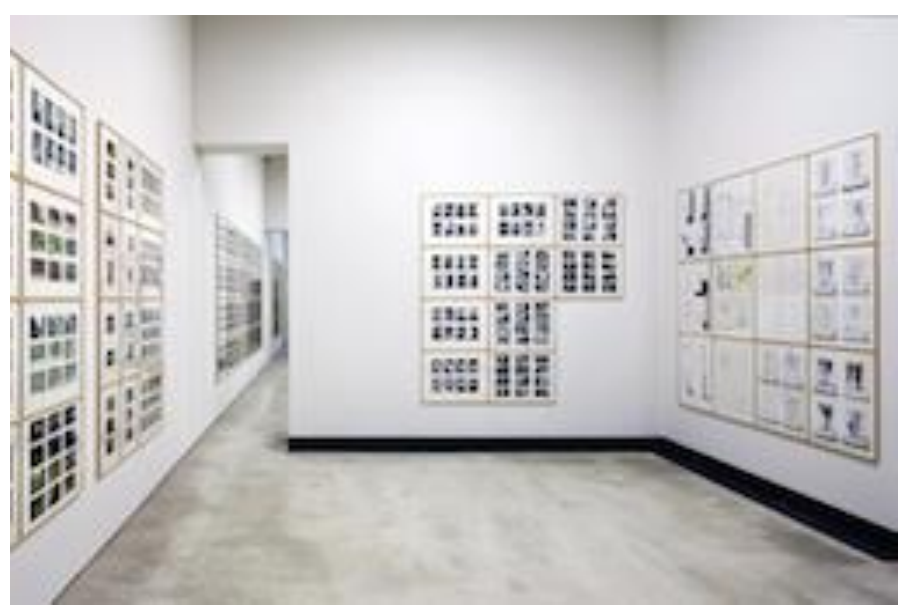

Atlas de Gerhard Richter

Artistas antecipam terremotos. O artista e o escritor são uma espécie de sismógrafo segundo (Thomas Mann). Percebem e dão a ver, de modo muito singular, que as antigas engrenagens do mundo rangem, desgastadas e corroídas... Que o mundo reclama sua inconformidade a velhas estruturas, medidas e modelos (CESAR, 2014, p. 13). Gerhard Richter assim o faz em Atlas, um arquivo não-morto, mas avivado por imagens desconexas, ajuntadas numa trama de ventos, rajadas, abalos. Um porto a lançar sempre, para o alto mar e para altos mares, de quem queira e se disponha a com ele navegar em partilhas e perdas, a penetrar em camadas escatológicas de uma contemporaneidades complexa, difusa, inconsistente. O sismógrafo registra tempos de chegada e várias ondas sísmicas, sensores a instalar em nós vários atos de cisma, rumina, fica absorto, inquieto, duvida, suspeita. As imagens nesse trabalho, experiências in continuum (John Dewey, 2010), são testemunhos da dissolução, do deslocamento e da conflagração de comunidades ali "emancipadas", em tempos atuais e de outrora, agora todos sobrepostos, esgarçando uns nos outros. Richter testemunha uma era na qual a memória não fica tributária, em dívida com o presente, são indícios, vestígios, sobras, fragmentos de um extenso que se tornam intensidades e turbulências. Não quer 


\section{Rerysta \\ A APOTHEKE}

dizer nada, mas maquinar (Gilles Deleuze). Segundo Deleuze, não existe a ideia em geral. A ideia é como uma festa, um acontecimento raro. A ideia já é destinada, como aquele que tem a ideia já é um destinado - há um certo dominio. Diria, diante de tantos possíveis no mundo, porque escolhemos uma questão para percorrer como ato criador durante uma vida inteira? As ideias, os assuntos ou temas são potenciais comprometidos com a expressão de si e de mundos. Richter guarda milhares de imagens durante anos e anos, para depois torná-las pintura, friccionando o conceito tradicional de pintura - "tintas sobre um suporte". Sempre desconfiei que o suporte não suporta - ele sustenta, é cúmplice, constituinte tanto quanto as tintas e/ou outros materiais. Ele a.tenta à materialidades outras. O tempo Richteriano é labiríntico: um agora comprimido, um presente intervalar de experiências captadas e com-figuradas, um futuro soterrado (Walter Benjamin). O espaço é ilimitado e virtual, pranchas pranchas pranchas em salas salas salas, mundos vastos mundos nada mudos. Mundo mundo vasto mundo, Se eu me chamasse Raimundo seria uma rima, não seria uma solução. Mundo mundo vasto mundo, mais vasto é meu coração (Carlos Drummond de Andrade). Atlas compõe e faz vazar mundos e mundos, em vastidões de mar, em vastidões de pessoas compartilhadas em vastidões de mundos simbólico/imaginados. Mundos proliferados em estados de suspensão.

o processo de criação só se efetiva na concretude, com dedicação e persistência, paixão e rigor, embate com um desconforto constante e permanente, enfrentamento entre o limiar de desistir e as frestas de fazer consistir. Na arte toleramos uma imensa energia a troco de nada. Não há função. É - inútil na inutilidade, mas ao mesmo tempo, a sustentação da vida, sustentação incessante exigindo atos de criação invenção efetuada e efetivada. Atlas compõe inúmeras dimensões 


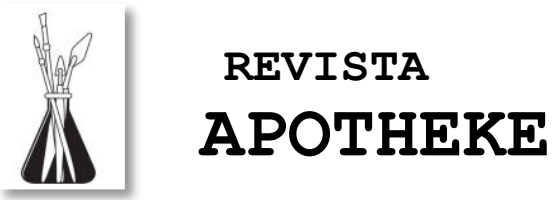

de uma biodiversidade ética, cultural, estética, estésica. Se somos um mínimo da biosfera, as milhões de imagens, em Atlas, fazem juntar e escapar muitos mínimos dos quais somos partesíntegras. Atlas nos monstra e nos devora, nos expõe e nos engole, nos faz ver e fugir para além de um "eu", um "euzinho", ou de um "nós". Atlas estraçalha "eus" e "nós". Exige cumplicidades criatíveis.

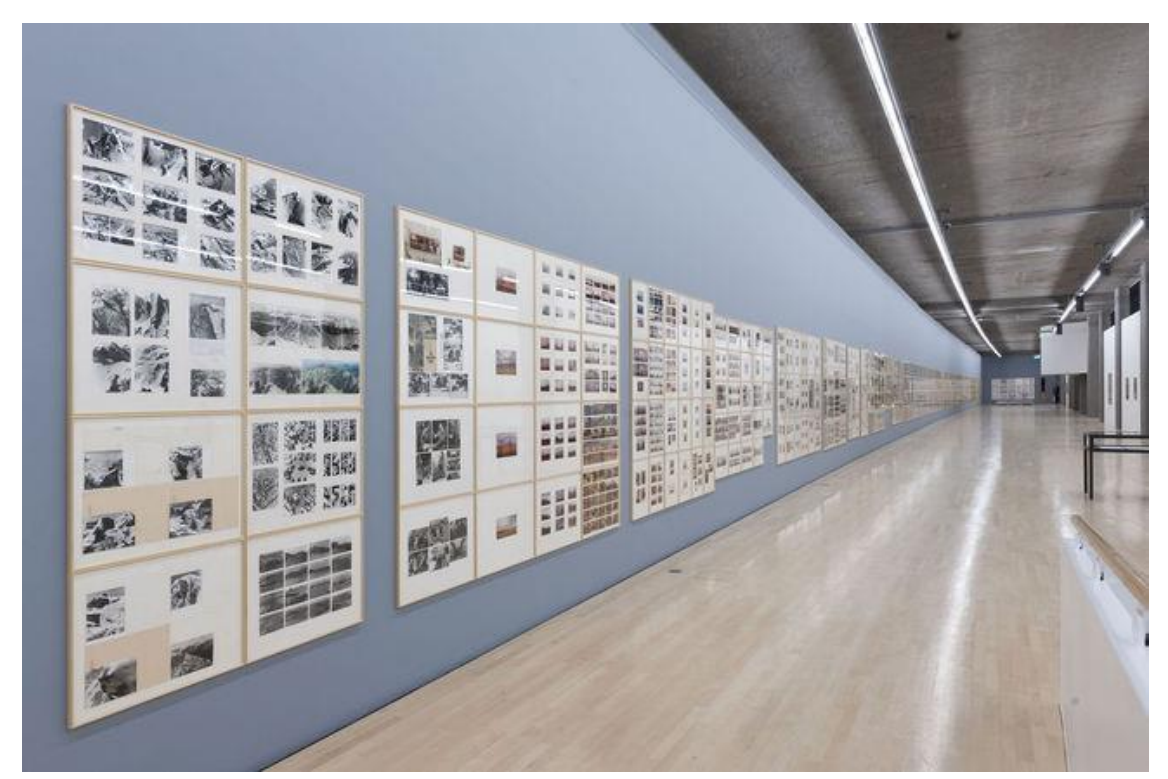

A arte sustenta e tenta atos permanentes, desloca para mundos outros e criações de "coisas que pensamos ainda não existir". Nesse texto, discuto o processo criador que se faz acontecer através dos atos de criação e invenção de conceitos, faturas, conexões com as histórias da arte e com campos diversificados do conhecimento. Entendo as histórias da arte no plural porque cada historiador/pesquisador escolhe e compõe agrupamentos de artistas, obras e experiências, tempos e conceitos para se colocar enquanto um sujeito pensante que agrega, discursa, mostra, embrenha elos e conexões com as "coisas" do mundo e as devolve e deposita, ao seu modo, como processualidades no mundo. O artista tenta em sua trajetória criadora, não resolver uma questão, mas viver as tensões nela imbricadas. Tenta manter fluxos, blocos de experimentação que visibilizem 


\section{《I}

essa necessidade pressuposta, imediata e imanente pedindo passagem. Para Craig Owens, o artista não inventa nada, confisca imagens. Para Suely Rolnik, o artista cria porque é 'obrigado a'. Concordo com essas falas. Na minha práxis, artista-professora-escritora, a todo instante sou convocada, seduzida e desafiada a dar forma às inquietações alicerçadas nas culturas, nos lugares, em tempos e situações nas quais estou imersa de modos pessoais/coletivos. Em artes visuais e sua enorme variação, o corpo vasa pelas mãos (vasa quer dizer, lama fina inconsistente. Prefiro a "vazar"). A tatilidade dá concretude às experimentações inventivas. A fatura exige imersão e mergulhos constantes com movimentos de suspensão, de intervalos, de distâncias para análise da trajetória criadora, que se dá em estados de experimentação dos acontecimentos, dos atos, das situações que nos fazem escapar do conforto. Arte é o desconforto, o inefável, o inverosssímel. O artista investe e debruça em camadas de artisticidades em processo, que mostram características e especificidades singulares. Transita entre polos convergentes e polos divergentes, polos de escape. Flutua em camadas de inesperados, de inseguranças, de instabilidades, de estar à deriva.

Volto a Deleuze, um criador só faz aquilo que tem absoluta necessidade. Cita Kurosawa e sua familiaridade com Shakespeare e com Dostoievski - os personagens de todos esses, cineasta e autores, estão presos a urgências. Há sempre uma urgência mais urgente. A fatura se dá no embate com os materiais, arrancando deles, o máximo de potência para que as combinatórias sustentem as necessidades do artista. Uma pintura não é do artista. Ela é o artista que, ao assinar, afirma duplamente ser ele mesmo, não o autor, mas um ser-pregado-na pintura. No decorrer do percurso de um artista conseguimos perceber os modos como seu trabalho se configura no mundo. As variáveis mantém linhas tênues que dão a ver escolhas e os modos de 


\section{ע|}

enfrentar as tensões para, com elas com-viver. Durante anos Richter (res)guarda suas urgências, as faz decantar para depois expô-las ao mundo, com fina ironia ética, estética, política. Somos seres biopolíticos (Peter Pál Pelbart). As estesias são acionadas incessantemente ao vivermos esse acúmulo a nos penetrar pelo olhar atento, pela suspensão do respiro, pelo corpo movente de quem debruça sobre Atlas. Richter faz parte de um grupo de artistas que, nos anos 60 e 70 trazem à tona a crise do sujeito no mundo contemporâneo. Michel Foucault chamou de minipoderes. Essa parafernália de imagens ativa, atiça e nos atira aos minipoderes num mundo dos maxipoderes, principalmente nos sistemas instituídos, da arte, das culturas, da educação, das sociabilidades. Captar mínimos do mundo são ações mini políticas de re-invenção de mundos e de vidas-em vivência.

Para André Malraux, a obra de arte é a única coisa que resiste à morte. A arte é o que resiste. O artista insiste, resiste, consiste. Deleuze afirma que a obra de arte é um ato de resistência. Uma pintura é uma re-existência afiada, afinada dia-a-dia na trajetória do artista. O ato de resistência tem duas faces: é humano e também ato de arte. Para Paul Klee, falta o povo... Não há obra de arte que não faça um chamado a um povo que, todavia, não existe (CESAR, 2014, p. 41). Arte é endereçamento de partilha a/com o outro. A arte solicita o julgamento, o olhar e a palavra. Arte seria uma imprecisão nomeada? Não seria nesse desamparo que a arte acontece? Um nós que implica, desde dois, até uma vasta comunidade? Existir é ser exposto, sair "de um si", de "uma identidade", expondo-se à exterioridade, à alteridade, à alteração. Em quantas camadas somos alterados por e/em Atlas? São muitas agregações, muitos com-postos coletivos e colaborativos. Existir é co-existir, singular/plural. Richter pluraliza, em suas combinatórias experimentais, as co-existências de um século, suas 


\section{APEISTA}

anterioridades e posterioridades. Somos minúsculas partículas da biosfera. Richter instaura proximidades e intimidades, compartilha instantes, dias, décadas. Instaura tipologias da distância, da proximidade, da intimidade, do sociável; um viver-junto com inúmeras modalidades. Reinventa a pintura, reinventa sociedades nos campos de "e...e...e...e"..., não no campo "disso ou daquilo". Propõe multiplicidades em contraste ao verbo "ser". e..e...e... é meio, conecta o estar entre coisas. A experimentação solitária, guardada, engavetada, só existe se pluralizada. No momento em que esses blocos de experimentação são expostos, expandidos para lugares outros, para além do atelier do artista, quer seja no sistema da arte ou nos outros espaços/ tempos, eles se publicizam, se tornam públicos, se efetuam no mundo. O vedor/leitor se torna cúmplice da criação. Passa a ser uma processualidade contaminada, a ser fabricada e maquinada por muitas camadas e inúmeras compartilhas, imensas e fugazes "compar-trilhas" que, em linhas de errâncias, gaguejam, desfalecem, descontrolam, escorrem, arrastam. Atlas não fala, escuta e aguarda (Deleuze, $1995)$.

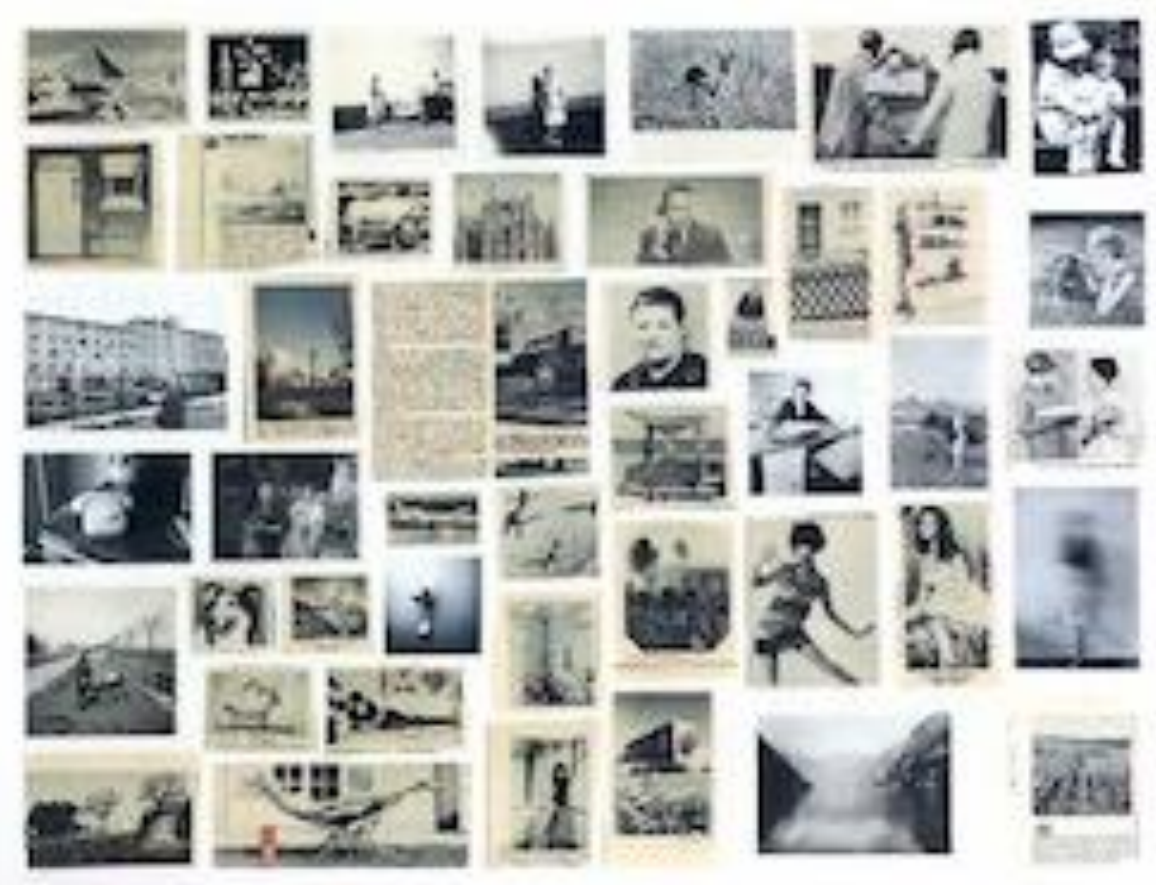

ISSN: 2447-1267 Santa Catarina, v.2, n.2, ano 2, fevereiro de 2016. 


\section{REVISTA \\ APOTHEKE}

Atlas - Detalhe

... o artista recolhe neste quadro seus companheiros pobres do chão:

a lata a corda a borra vestígios de árvores, etc. Manoel de Barros

Muitos artistas trabalham com arquivos, vestígios e armazenamento de camadas camadas camadas sócio-culturais. Gerhard Richter, em Atlas, mostra uma condensação de recortes de jornais, revistas e mídia impressa, desenhos, colagens, pinturas, fotos, esboços guardados entre 1962 e 2013: No começo eu tentava acomodar tudo que havia colecionado, entre o lixo e alguma coisa importante para mim e uma certa dose do que 'acontece' por aí (Richter). Atlas é um trabalho de coleta, organização e amostragens, working in progress, como os trabalhos de Hélio Oiticica, sempre para além de um "si", uma máquina de guerra, uma mistura de corpos e de corpus em risco a produzir desvios, sem enfretamento frontal, a escapar do confronto direto e especular; viagens e encontros sem "bíblias". São cerca de 802 agrupamentos em folhas de papel e mais de 5.000 imagens heterogêneas, um contingente empírico e uma estrutura taxionômica de 50 anos. Agregam diferentes fases da vida e do trabalho de Richter e inúmeras "peles" de contextos históricos, econômicos, familiares, culturais, mundo(s) afora. As imagens mostram um acervo, do privado ao público e um projeto enciclopédico, pessoal, coletivo do público ao privado. Cada vedor compõe mundos in-existências. Estamos todos imersos, enfiados nessas imagens século vinteanas. Estamos todos imersos em companheiros pobres do chão, em borras, vestígios, sobras, resíduos. O que é uma imagem de jornal, a ser lida e descartada? Ele as coleta. O que é um esboço? Seria um pre-texto? Ele os guarda, tornam-se com-textos visuais. A acumulação sugere gráficos de ensino, 


\section{《)}

ferramentas de estruturas educativas, ilustrações científicas, técnicas encontradas em livros didáticos e catálogos, organização de materiais em arquivos. A diferença do Atlas de Richter, é a tensão interna entre o extraordinário rigor formal e a dificuldade de estabelecer temas em comum. A cada exposição as imagens são agrupadas de diferentes modos. Numa mesma prancha aparecem fragmentos de papel higiênico e fotos do Holocausto, campos de concentração, paisagens, fragmentos de pinturas, pornografia, fotos de famílias, flores, cidades... Coincidem episódios pessoais e eventos histórico/culturais/mundiais. Richter, em Atlas, condensa, mostra e fabrica fugas para lugares outros. Instantes de diaa-dia além de matéricos, reinventam a pintura informal e a pintura abstrata. Sua constante paleta são as imagens do mundo, transformadas em imagens enciclopédicas, agora no mundo, de modos outros - ficam, fincam em nós, de nós escapam, são peles/pelancas. A complexidade, a intensidade e a densidade criam crostas de escapatórias sem fixação, sem rigidez, sem reconhecimento. Uma fura a outra e outras e outras. Há uma prorrogação infinita. O olhar não pára, o corpo dispara, os contextos esmagam. Eu estava surpreso com a fotografia que usamos tão maciçamente todos os dias. Vi um outro caminho, livre de critérios convencionais e associei com arte, sem estilo, sem composição, sem julgamento. Num primeiro momento era 'pura pintura'. A pintura como fotografia (Gerhard Richter). Atlas é extensão, vasteza, dilatação imensa e disforme, rigor volumoso, resistência acimentada que não representa imagens de anos a fio, mas presenta uma iconografia de imagens vivas. É andaime século vinteano, sustenta, ampara e faz repousar "realidades inquietas". O excesso, o acúmulo e a ordenação constantes, vão além de arquivos, são territórios na arte contemporânea, agrupados por ousadias de ajuntamentos, uma topologia como cadáver da experiência (PESSANHA, 2015, p. 
219) .

A arte é na realidade, esse elo que falta, não o elo que existe. Arte é o que se vê, arte é a lacuna. A arte é um ponto obscuro, uma rede de relações. (CESAR, 2014, p. 67).

Atlas ativa estados de mediação e das inventAções, configura mapa(s) de encontros, acontecimentos, sensAções a devir(es), e a maquinar corpos vibráteis. Ativa os estados do fazer e do "imagizar" (imagens com imaginação e ação), tema, fatura, história(s) da arte, ações compar-trilhadas nos sistemas da arte, das culturas e das situações mundiais. Ativa estados do ser e do imaginar pessoalidades tecidas em contextos, em situações, em portos à deriva, alto mar sempre à distância. Nele chego. Dele escapo. Ativa micro-estesias e micropolíticas. Mantém e atiça curiosidade, tensão, ousadia, deslocamento de estar ali pregado numa saturação imagética in. sustentável.

os atos estéticos são configurações da experiência, ensejam novos modos de sentir e novos modos de subjetivação política.

A arte é um testemunho do encontro com o irrepresentável que desconcerta todo pensamento, um testemunho contra a arrogância da grande tentativa estético-política do devir-mundo do pensamento.

A arte é um modo de articulação entre maneiras de fazer

e formas de visibilidade, modos de pensabilidade/ideia da efetividade do pensamento. Jacques Rancière

Nicolas Bourriaud (1965), defende que em um mundo em que o mercado, a comunicação, o espetáculo engolem os contatos humanos em espaços de controle, transformando os laços sociais em produto e imagem, a arte permanece em território rico de experimentações sociais, criando micro utopias de proximidade, micro territórios relacionais. Formas de visibilidade e de pensabilidade são, em nossos cotidianos, ações a devir. 


\section{Rerysta \\ (4) APOTHEKE}

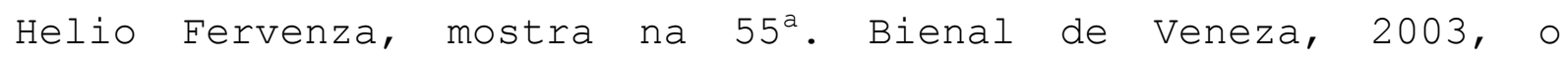
trabalho: (peixe, sombra) dentrofora (do céu da boca) d'água ( , ). Fervenza se insere entre os artistas contemporâneos que produzem arte e teorizam sobre suas produções artísticas. Propõe uma obra plástico-teórica desenvolvida a partir de noções de espaço, vazio, pontuação, apresentação, mostrar/esconder. Nas instalações agrega fotografias, objetos, gravuras, impressos, recortes em vinil, misturando pontuações da escrita junto a imagens. Afirma, o espaço da exposição é um entrecruzamento de dispositivos que operam sobre a visualidade. Toda exposição implica uma apresentação. Cria o conceito de Auto-apresentação que enfatiza o processo de criação e a vivência pessoal, ação e situação como arte. Noções de pontuação, inscrição e intervalo são interrelacionadas ao espaço expositivo. O ponto é tomado como menor forma visível até a pontuação como parenteses de grandes formatos adesivados em vinil, junto a imãs, pregos, anzóis, fios metálicos e peixes usados para pesca. O espaço expositivo comporta, mostra, presentifica articulações conceituais, estéticas e estésicas, nas quais temos que adentrar. Não basta passar, passear por ele. O espaço nos obriga a debruçar sobre as camadas ali visivas, que vão além de uma visualidade, exigindo exercícios de visibilidade e de lesibilidade. 0 espaço é alargado, expandido, alastrado de ações além do "constatado", do "conferido", do "já sabido". Fervenza nos coloca em situação e em atos de criação, junto ao seu processo e percurso criativo e expositivo - presenças outras. (peixe, sombra) dentrofora (do céu da boca) d’água (, ) 


\section{R| Revrssa \\ A APOTHEKE}
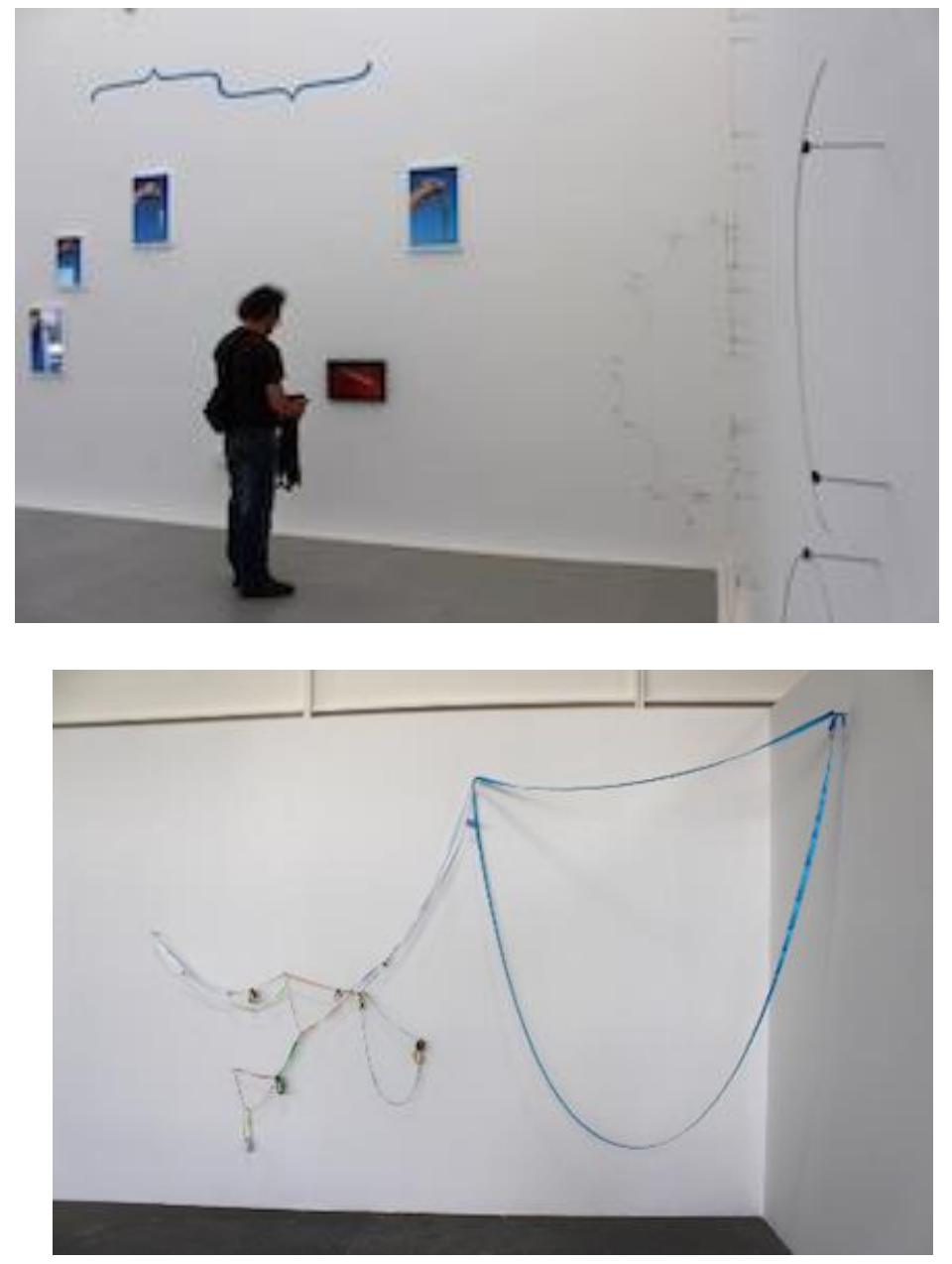

Helio Fervenza, Detalhe

Richter e Fervenza desinventam objetos. O pente, por exemplo. Dar ao pente funções de não pentear. Até que ele fique à disposição de ser uma begônia. Ou uma gravanha (BARROS, 2007). Nos dois artistas e nas duas obras, temos que penetrar em begônias e gravanhas, além de pentes para pentear desinventar a nós e aos instituídos dentro de sistemas, quer da arte, da educação, das culturas. Segundo Gregory Bateson, existe uma ecologia das ideias danosas, assim como das ervas daninhas.

Atlas e (peixe, sombra) dentrofora (do céu da boca) d’água (, ), são das instâncias das ervas daninhas.

Nesse momento podemos pensar em vários territórios, o das palavras e o das imagens, entrecruzados aos nomes dos 


\section{X|}

trabalhos; território das experimentações-mediações estéticas e estésicas e os modos como nos atiçam e vão se constituindo; território das subjetivações e das cognições, nas camadas sobrepostas; território das densidades, levezas, multiplicidades, fugas, escapes, inesperados; território das terras a devir, de cada leitor, vedor, fruidor, interlocutor(es); território das fábricas de ações que não existem; território das compar-trilhas e das ações colaborativas.

o artista, à força, cria uma forma, dá forma a um impacto. A forma dada possui e faz um sentido. A arte possui a capacidade de implicar o Outro, possui uma dimensão ético/política. Hélio Oiticica em 1992 chocou Paris, na Exposição no Jeu de Paume. O cotidiano, o banal, a atualidade, a informação, os medos, os receios, não quero ultrapassá-los sem confrontá-los, quero tocar no problemático o mais diretamente possível, quero agir responder, 'obrigar o outro a responder': qual a minha posição? (nas palavras de Hirschhorn). Atlas e (peixe, sombra) dentrofora (do céu da boca) d'água, são blocos de experimentação entre Um e Outros. Richter performatiza o diaa-dia, as conexões e as tornam escapatórias que cutucam, nos tecem, nos des.a.fiam. As palavras nos inquietam e as forças criatíveis nos impulsionam. Fervenza conecta inutilidade aos imprevisíveis.

Os artistas citados nesse texto, gestam trabalhos que passam pela topologia do atravessamento, da transição, do abismo e da visita epifânica (PESSANHA, 2015, p. 217). São obras/travessias. Poéticas de brotamentos. Ética de encontros imprevistos. Os textos visuais são planetas/textos, como diz Juliano Pessanha. São fendasffora e o surgimento de alteridades banidas. Fenda-rachadura do não-datado, do nãoconfigurado, a devir pinturas-pintadas. Para cada mundo existe um antimundo e um contramundo. Para todo não mundo, uma 


\section{\.}

passagem. Implosão e explosão contínuas, instabilidade perpétua (PESSANHA, 2015, p. 223), pinturas a pintar.

\section{REFERÊNCIAS BIBLIOGRÁFICAS}

BARROS, Manoel de. Gramática expositiva do chão. $6^{a}$. ed. Rio de Janeiro/São Paulo, Record, 2007.

Janeiro/São Paulo, Record, 2007.

CESAR, Marisa Flórido. nós, o outro, o distante, na arte contemporânea brasileira. Rio de Janeiro, Ed. Circuito, 2014.

DELEUZE, Gilles. Mil Platôs, v. 1 e v. 2. São Paulo, Ed. 34, 1995.

PESSANHA, Juliano Garcia. Testemunho transiente. São Paulo, Cosac Naify, 2015.

PESSOA, Fernando. Tabacaria e outros poemas. $2^{a}$. ed. Rio de Janeiro, Ediouro, 2006.

RANCIÈRE, Jacques. A partilha do sensível. São Paulo, Ed. 34, 2002 .

ANDRADE, Carlos Drummond. Poema de sete faces.

wWw.algumapoesia.com.br

DELEUZE, Gilles. O ato de criação.

www.ladcor.files.wordpress.com

www.heliofervenza.net

Lucimar Bello, Artista plástica, vive e trabalha em São Paulo. Exposições Individuais e Coletivas, Brasil, Argentina, Chile, Portugal, Espanha, Japão, Cuba, China (Instalações, Desenhos, Gravuras, Vídeos, Fotografias, Performances). Doutora em Artes pela ECA/USP. Pós-doutora em Comunicação e Semiótica pelo COS/PUC/SP (2001). Pós-doutora no Núcleo de subjetividade da PUC/SP (2008). Professora na FURB, Blumenau (1971-76). Professora na UFU, Uberlândia (1977-1996). 